\title{
STOKES-ADAMS ATTACKS IN ACUTE RHEUMATIC CARDITIS
}

\author{
BY \\ T. C. GIBSON AND J. P. HUGHES \\ From the Cardiac Department, The London Hospital
}

In those exceptional cases of acute rheumatic carditis in which severe grades of heart block are met, the possibility of Stokes-Adams attacks must exist. This complication is, however, rarely seen and few examples have been recorded.

Schuster (1896) described the case of a boy aged 4 years who, during acute articular rheumatism, was found to have a pulse rate of 32 associated with fainting attacks. Stokes-Adams attacks were observed by Stern (1944) in a patient with acute pericarditis. Lukl and Cee (1953) noted syncopal attacks with complete heart block preceding the joint manifestations of acute rheumatic fever. Other cases have been described by Faulkner (1930), Salvesen (1932), Dumas (1938), Giraud et al. (1938), and Green and Bennett (1945). We describe a case that came under our own observation.

Case Report. The patient, a married woman, aged 22, was admitted to hospital with a history of a sore throat two weeks before, and for one week her right wrist had been swollen and painful. In the past she had rheumatic fever at the age of 7 , and five subsequent attacks of fever and joint pains. She had two children, aged 6 and 5, without complication. Digitalis had been given intermittently for the last seven years, but not for several months prior to admission.

On examination the temperature was $101.5^{\circ} \mathrm{F}$., and the right wrist was swollen, tender, red, and warm. No other joints were affected and there were no rheumatic nodules. The pulse rate was 100, irregular, and of small volume. The jugular venous pressure was not raised. The apex beat was in the fifth intercostal space just outside the mid-clavicular line. In the mitral area there was a loud first sound, a pansystolic murmur, a mitral opening snap, and a short mitral diastolic murmur. No early diastolic murmur was heard. The pulmonary component of the second sound was accentuated. Blood pressure was normal. The E.S.R. (Westergren) was $123 \mathrm{~mm}$./1 hour. The cardiogram showed partial heart block where every third or fourth auricular beat was not conducted (Fig. 1A). Radiologically the heart was enlarged. An exacerbation of carditis with mitral stenosis and incompetence was diagnosed.

Progress. Symptomatic improvement followed salicylate therapy, but five days after admission the jugular venous pressure was raised $5 \mathrm{~cm}$. above the sternal angle with the patient at $45^{\circ}$. There was no clinical evidence of pericardial effusion and 2 grains of digitalis leaf was given daily. The cardiogram again showed partial heart block with dropped beats every second, third, fourth or even fifth auricular beat not being conducted (Fig. 1B).

Eleven days after admission she suddenly became unconscious, but seven minutes later, after oxygen and artificial respiration she recovered with a good peripheral circulation and normal reflexes. The pulse rate was then 42, and a tentative diagnosis of a Stokes-Adams attack was made. Digitalis therapy was discontinued. During the night she had two further attacks which were epileptiform in character and she was given ephedrine hydrochloride. Later in the day a typical Stokes-Adams attack was witnessed by one of us, in which the patient first vomited, then became unconscious for twenty seconds, during which time no radial pulse could be felt and no heart sounds were heard on auscultation. Return to consciousness was heralded by a diffuse facial flush and a pulse rate of 70 to 80 for two to three minutes before returning to 40 a minute once more. She was given atropine sulphate (1/60 grain) four hourly, which raised the pulse rate to 80 , but after three hours her pulse rate again returned to 40 to 50 . Atropine dosage was altered to $1 / 100$ gr. two hourly. No further Stokes-Adams attacks occurred. The cardiogram then (Fig. 1C) showed 2:1 heart block, and (Fig. 1D) complete heart block a week later. Later she reverted to partial 
heart block with dropped beats; 12 days after this the cardiogram showed latent heart block with a $\mathbf{P}-\mathbf{R}$ interval of 0.34 second, and after two months the P-R interval was normal.

One month after admission the joint pains had gone, the temperature was normal, and the E.S.R. was $35 \mathrm{~mm}$./hour. An early diastolic murmur was heard on occasion at the left sternal edge. Two months after admission she was sent to a convalescent home, her E.S.R. having been below $10 \mathrm{~mm}$./hour for three weeks.

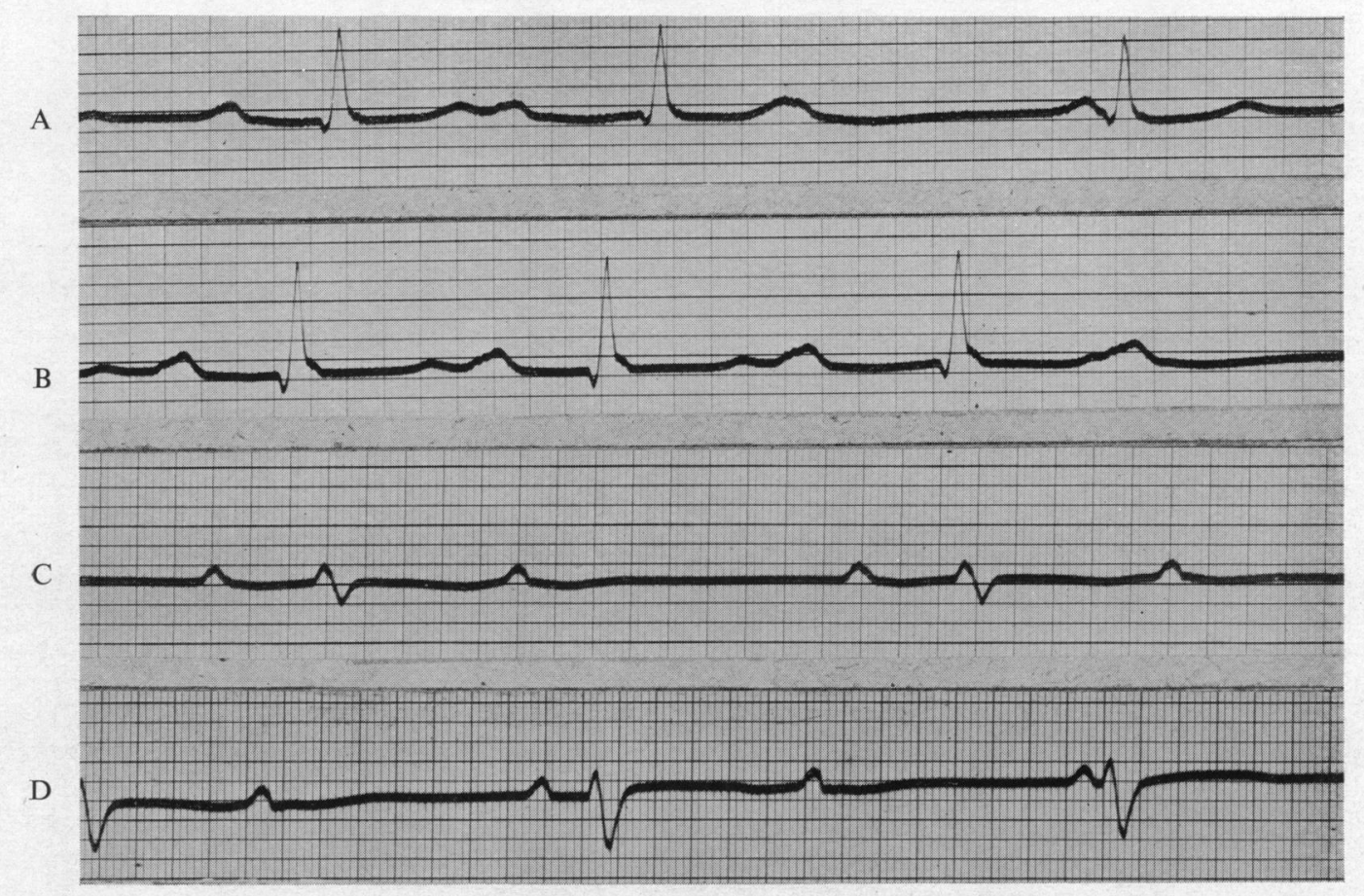

FIG. 1.-(A) and (B) Partial heart block with dropped beats, (C) $2: 1$ heart block, (D) Complete heart block.

\section{Discussion}

Complete heart block is rarely met with in rheumatic fever. Parkinson et al. (1920) recorded partial heart block in 15 out of 50 cases of rheumatic fever, 4 of which developed dropped beats. Once the acute rheumatic process has subsided the disorder of conduction usually disappears although paroxysmal complete' heart block has been noted in association with Stokes-Adams attacks in patients with chronic carditis (Graybiel and White, 1936; Campbell, 1944). In practically all cases where Stokes-Adams attacks have been reported as a complication of rheumatic fever there was no previous rheumatic history with the exception of a woman aged 45 (Dumas, 1938) and the present case, in both of whom there was an established lesion of the mitral valve. The attacks were infrequent and occurred during the active phase of rheumatic carditis, usually over a period of not longer than 48 hours; recurrent attacks were, however, observed by Green and Bennett (1948) whenever their patient relapsed with pyrexia and joint pains. In those cases where serial cardiograms were available it was common to find partial heart block with dropped beats, $2: 1$ heart block, and complete heart block in no ordered sequence over a period of a few days and it was during this time that Stokes-Adams attacks occurred.

The cardiogram usually returned to normal within two to eight weeks. Apart from the presence of varying grades of heart block there seemed no further reason why Stokes-Adams attacks should occur in these cases. Digitalis may be a factor where severe grades of heart block occur 
in acute inflammatory lesions of the myocardium, and in experimental animals Cushny (1925) observed that raising the temperature of the heart rendered them more susceptible to digitalis. Our patient had received digitalis folia, 1 grain twice daily, for six days preceding the StokesAdams attacks, and in two further cases digitalis had been administered (Dumas, 1938; Giraud, 1938). Although in the remaining six cases there is no mention of digitalis being used, it is possible that its administration may be of significance in the precipitation of Stokes-Adams attacks in acute rheumatic carditis.

\section{Summary}

A case of rheumatic fever is reported where transient complete and partial heart block was associated with Stokes-Adams attacks. There was eventual electrocardiographic recovery. This complication of rheumatic fever is unusual and only eight reports of similar cases were found. No convincing evidence as to the cause of the Stokes-Adams attacks was found on reviewing these cases.

We wish to thank Dr. Wallace Brigden for his permission to publish this case and for his helpful advice.

\section{References}

Campbell, M. (1944). Brit. Heart J., 6, 69.

Cushny, A. R. (1925). The Action and Uses in Medicine of Digitalis and its Allies. 1st ed., London. Dumas, A. (1938). Lyon Med., 162, 309.

Faulkner, J. M. (1930). New Eng. J. Med., 202, 1252.

Giraud, P., Erlande, and Bernard, R. (1938). Marseille med., 1, 591.

Graybiel, A., and White, P. D. (1936). Amer. J. med. Sci., 192, 334.

Greene, J. A., and Bennett, A. W. (1945). Amer. Heart J., 30, 415.

Lukl, P., and Cee, C. (1953). Lekar. Listy. Brno, 8, 485.

Parkinson, J., Gosse, A. H., and Gunson, E. B. (1920). Quart. J. Med., 13, 363.

Salvesen, H. A. (1932). Acta med. Scand., 78, 189.

Schuster, - (1896). Deutsch. med. Wchnschr., 22, 484.

Stern, V. S. (1944). Brit. Heart J., 6, 66. 